\title{
The Birth of Bariatric Endocrinology and the Coming of Age of Obesity Medicine
}

\author{
J Michael Gonzalez-Campoy \\ Minnesota Center for Obesity, Metabolism and Endocrinology, Eagan, US
}

\begin{abstract}
The number of publications about obesity has increased geometrically over the past couple of decades. The knowledge that adipose tissue is an endocrine organ gave birth to the field of bariatric endocrinology. The concept that adipose tissue may become diseased, and thus contribute to the genesis of metabolic disorders, including hyperglycemia, dyslipidemia, hypertension, male hypogonadism, and cardiovascular disease, constitutes adiposopathy. The goals of treatment for people with overweight and obesity are to decrease the burden of fat mass (adiposity), and to treat adiposopathy (i.e. to return adipose tissue function to normal). As a society, we must overcome the social, political and economic obstacles that prevent patients with overweight or obesity from gaining access to needed medical care.
\end{abstract}

\section{Keywords}

Bariatric endocrinology, obesity, adiposopathy, vagal blockade, intra-gastric balloon, weight loss medications, bariatric surgery

Disclosure: J Michael Gonzalez-Campoy has received speaker honoraria from Amylin, Astra Zeneca, Vivus, Eisai, Janssen, GSK, Takeda, Novo Nordisk and Shire. He has received research grants from Sanofi-Aventis, Novo Nordisk, Astra-Zeneca, Boehringer Ingelheim, Ipsen, Eli Lilly, Bristol Myers Squibb and Mannkind. He is a consultant for ValenTx, Corcept and Novo Nordisk. This article is a short opinion piece and has not been submitted to external peer reviewers. No funding was received in the publication of this article. open Access: This article is published under the Creative Commons Attribution Noncommercial License, which permits any noncommercial use, distribution, adaptation, and reproduction provided the original author(s) and source are given appropriate credit.

Received: April 5, 2016 Published Online: April 15, 2016 Citation: US Endocrinology 2016;12(1):10-1 DOl: http://doi.org/10.17925/USE.2016.12.01.10 Correspondence: J Michael Gonzalez-Campoy, Minnesota Center for Obesity, Metabolism and Endocrinology, PA (MNCOME), 1185 Town Centre Drive, Suite 220, Eagan, MN 55123, US. E: drmike@mncome.com

A search of PubMed shows that in 1960, the year I was born, there were 110 publications on obesity. In 1991, the year I graduated from Mayo Medical School, the number had risen to 406 publications. By contrast, in 2015 there were 5470 publications on obesity. The last quarter of a century has led to the recognition of a world-wide epidemic of overweight and obesity, with a rise in all their complications. ${ }^{1-3}$ And with this recognition came the need to understand the underlying physiology and pathophysiology, and the eventual development of therapeutic interventions. ${ }^{4-6}$

It is now clear that the accretion of adipose tissue (adiposity) leads to physical complications (i.e. sleep apnea, gastroesophageal reflux disease, degenerative osteoarthritis, and dermopathy). It is also universally recognized that adipose tissue is not just an energy storage organ. Rather, adipose tissue is an endocrine organ which actively makes and responds to hormones. As such, adipose tissue is a major contributor to energy homeostasis.

An emerging concept is that derangements of adipose tissue function contribute to the genesis of metabolic diseases (i.e. diabetes, hypertension, dyslipidemia, cardiovascular disease). My colleague, Harold Bays, introduced the concept of adiposopathy (sick fat) into the medical literature.7,8 Adiposopathy defines the anatomic and functional changes that lead to adipose tissue dysfunction, and thus contribute to metabolic diseases.
Adiposopathy is anatomically manifested by adipocyte hypertrophy, visceral adiposity (best measured by the waist circumference), growth of adipose tissue beyond its vascular supply, increased number of adipose tissue immune cells, and ectopic fat deposition (in other body organs). Functionally, adiposopathy is manifested by impaired adipogenesis, heterogeneous distribution of adipose tissue (i.e. preferential accumulation of intra-abdominal, visceral fat), adipocyte lipolysis in excess of lipogenesis, increased free fatty acids, pathogenic adipose tissue endocrine responses (i.e. hypoadiponectinemia and hyperleptinemia), pathogenic adipose tissue immune responses, and pathogenic crosstalk between adipose tissue and other organs. ${ }^{8-11}$

Bariatric endocrinology was born from the need to address adipose tissue as an endocrine organ, and to study the role of adiposopathy in the etiology of metabolic diseases. Further, bariatric endocrinology focuses on the development of medical interventions that return adipose tissue normal. Whereas the loss of adipose tissue mass improves the complications of adiposity, the treatment of adiposopathy, independent of fat mass, is now a primary treatment target. ${ }^{12}$

Surrogate measures of adipose tissue function, including insulin resistance, increased waist circumference, hypertriglyceridemia and low levels of the high density lipoprotein cholesterol (the elements of the dysmetabolic 
syndrome) are giving way to direct measures. The measurements of leptin and adiponectin, and their ratio, trended over time, reflect adipose tissue health. Leptin levels rise with increasing fat mass, whereas a drop in adiponectin indicates a decline in function of adipose tissue. A widening ratio of leptin to adiponectin over time documents a deterioration of adipose tissue health (worsening adiposopathy). On the other hand, narrowing of the ratio indicates improvement in adipose tissue health. Although the assays for these hormones are available now, they are not standardized, and most physicians are not fluent in their use. In addition, direct measurements of visceral adipose tissue (i.e. with dual energy X-ray absorptiometry), make quantitation of regional fat distribution possible.

Obesity is a chronic, genetically programmed disease. The environment in which we live, referred to as an obesogenic environment, certainly plays a major permissive role in the expression of the many genes that lead to the accumulation of fat mass. As with any other chronic disease, obesity may be treated, managed, controlled, and even put into remission. But it cannot be cured. Patients need to understand this premise, because the treatment of obesity is life-long. The implementation of models of chronic disease management for the treatment of obesity provides the appropriate framework for success. Thus, obesity treatment should include all available treatment modalities, from lifestyle changes that include better nutrition and more physical activity (NOT diet and exercise), to pharmacotherapy, to the use of devices, and surgery for weight loss. ${ }^{13-16}$

Under the leadership of Bob Kushner, the American Board of Obesity Medicine was established in 2011 "to serve the public and the field of obesity medicine through the establishment and maintenance of criteria and procedures for examination and certification of candidate physicians who seek recognition of their accomplishments in obesity medicine". ${ }^{17}$ Organizations which have dealt with obesity as a disease-including The Obesity Society (TOS), formerly the North American Association for the
Study of Obesity (NAASO); the American Society of Bariatric Physicians (ASBP), now the Obesity Medical Association (OMA); and the American Society for Bariatric and Metabolic Surgery (ASBMS), formerly the American Society for Bariatric Surgery (ASBS) — have been joined by many specialty societies to address obesity care.

The fruitful partnerships of physicians and pharmaceutical and biotechnology companies, recognized by the Association of Clinical Researchers and Educators (ACRE) as a healthy working relationship that advances medicine, ${ }^{18}$ has brought to the market newer and safer treatment options for obesity. There are currently five US Food and Drug Administration (FDA) approved medications for the treatment of obesity as a chronic disease. More compounds are in clinical trials. In addition, procedures such as vagal blockade and intra-gastric balloon placement, are already available for selected patients. ${ }^{19,20}$ Bariatric surgery has been refined, with most procedures now being done laparoscopically.

The single major obstacle to the effective implementation of obesity treatment programs is a lack of coverage. Both in the US and abroad, payment for obesity care is mostly excluded from coverage. It starts with federal institutions, carries through to state programs, and is mirrored by most private insurance. Despite recognition of the economic costs of obesity now, and the cost savings of treating it over time, patients do not have access to necessary medical care. It will take legislation to change antiquated federal agency rules before real progress can be made. The widespread implementation of obesity treatments will readily follow these political and economic changes.

For now, it is exciting to me that a new generation of physicians is learning about overweight, obesity, and adiposopathy as diseases that can and should be diagnosed and treated. Obesity medicine has come of age, and bariatric endocrinology is here and growing!
1. Apovian $\mathrm{CM}$, The Obesity Epidemic--Understanding the Disease and the Treatment, N Eng/ I Med, 2016:374:177-9.

Stamler J, Epidemic obesity in the United States, Arch Intern Med, 1993:153:1040-4.

3. James PT, Leach R, Kalamara E, Shayeghi M, The worldwide obesity epidemic, Obes Res, 2001;9(Suppl 4):228S-33S.

4. Proenca AR, Sertie RA, Oliveira AC, et al., New concepts in white adipose tissue physiology, Braz I Med Biol Res, 2014;47:192-205.

5. Armani A, Marzolla V, Fabbri A, Caprio M, Cellular mechanisms of MR regulation of adipose tissue physiology and

Izzi-Engbeaya C, Salem V, Atkar RS, Dhillo WS, Insights into Brown Adipose Tissue Physiology as Revealed by Imaging Studies, Adipocyte, 2015;4:1-12

7. Bays H, Adiposopathy, metabolic syndrome, quantum physics, general relativity, chaos and the Theory of Everything, Expert Rev Cardiovasc Ther, 2005:3:393-404.

8. Bays HE, Gonzalez-Campoy JM, Henry RR, et al., Is adiposopathy (sick fat) an endocrine disease? Int I Clin Pract, 2008:62:1474-83

9. Bays HE, Adiposopathy is "sick fat" a cardiovascular disease?, J Am Coll Cardiol, 2011;57:2461-73.
10. Bays HE, Gonzalez-Campoy JM, Adiposopathy. In: Friedberg E, Castrillon DH, Galindo RL, Wharton K, editors, New-Opathies, World Scientific, 2012:105-68

11. Bays HE, Gonzalez-Campoy JM, Bray GA, et al., Pathogenic potential of adipose tissue and metabolic consequences of adipocyte hypertrophy and increased visceral adiposity, Expert Rev Cardiovasc Ther, 2008;6:343-68.

12. Gonzalez-Campoy JM, Richardson B, Richardson C, et al., Bariatric endocrinology: principles of medical practice, Int J Endocrinol, 2014:917813.

13. Gonzalez-Campoy JM, St Jeor ST, Castorino K, et al., Clinical practice guidelines for healthy eating for the prevention and treatment of metabolic and endocrine diseases in adults: cosponsored by the American Association of Clinical Endocrinologists/the American College of Endocrinology and the Obesity Society, Endocr Pract, 2013;19 (Suppl 3):1-82.

14. Bays HE, Laferrere B, Dixon J, et al., Adiposopathy and bariatric surgery: is 'sick fat' a surgical disease? Int I Clin Pract, 2009:63:1285-300.

15. Apovian CM, Aronne $\mathrm{L}$, Bessesen $\mathrm{DH}$, et al., Pharmacological management of obesity: an endocrine society clinical practice guideline, J Clin Endocrinol Metab, 2015;100:342-62.

16. Mechanick JI, Youdim A, Jones DB, et al., Clinical practice guidelines for the perioperative nutritional, metabolic, and nonsurgical support of the bariatric surgery patient--2013 update: cosponsored by American Association of Clinical Endocrinologists, the Obesity Society, and American Society for Metabolic \& Bariatric Surgery, Endocr Pract, 2013;19:337-72.

17. American Board of Obesity Medicine, History, 2016. Available at: http://abom.org/history/ (accessed April 6, 2016).

18. Weber MA, Black HR, Fonseca R, et al., Association of Clinica Researchers and Educators a Statement on Relationships between Physicians and Industry, Endocr Pract, 2012;18:102937

19. Ikramuddin S, Blackstone RP, Brancatisano A, et al., Effect of reversible intermittent intra-abdominal vagal nerve blockade on morbid obesity: the Recharge randomized clinical trial, JAMA 2014;312:915-22.

20. Ponce J, Woodman G, Swain J, et al.. The REDUCE pivotal trial: a prospective, randomized controlled pivotal trial of a dual intragastric balloon for the treatment of obesity, Surg Obes Relat Dis, 2015;11:874-81. 